\title{
SPATIOTEMPORAL ANALYSIS OF THE URBAN COOLING ISLAND (UCI) EFFECT OF WATER SPACES IN A HIGHLY URBANIZED CITY: A CASE STUDY OF ILOILO RIVER AND ADJACENT WETLANDS
}

\author{
J.A. Cruz ${ }^{1 *}$, J.A. Santos ${ }^{1}$, J. J. Garcia ${ }^{1}$, A. Blanco ${ }^{1,2}$, A. D. Moscoso ${ }^{1,3}$ \\ ${ }^{1}$ Training Center for Applied Geodesy and Photogrammetry, University of the Philippines, Diliman, Quezon City, 1101, Philippines \\ - johndrew.cruz@gmail.com \\ 2 Department of Geodetic Engineering, University of the Philippines, Diliman, Quezon City, 1101, Philippines \\ ${ }^{3}$ School of Technology, University of the Philippines Visayas, Miag-ao, Iloilo, 5023, Philippines
}

\section{Commission IV}

KEY WORDS: Urban Heat Islands, UCI Indices, Land Surface Temperature, Landsat, Remote Sensing, Geographic Information Systems, Iloilo City

\begin{abstract}
:
Iloilo City, a highly urbanized city in the Philippines, experiences intensified climate change impacts due to the Urban Heat Island (UHI) phenomenon, one of which is the significant increase in temperature. To mitigate UHI, recent studies investigated the cooling effect of water bodies due to its higher rate of evapotranspiration compared to green spaces. This study aims to spatiotemporally assess the Urban Cooling Island (UCI) effect of Iloilo River and adjacent wetlands on the surrounding microclimate using geospatial techniques. Landsat images were processed to generate land surface temperature (LST) and land cover layers of the study area for the years 1994, 1998, 2003, 2005, 2013, 2016, and 2019. UCI Scale (influence range of the cooling effect), Temperature Difference (difference in temperature between water space and the area within the UCI scale), and UCI Intensity (temperature gradient within the UCI scale) were calculated using multiple-ring buffers with 50-m interval to quantify variations in cooling effect of the water space at distinct surrounding regions over a long time period. Results of the study show that wetland area has a weak negative relationship with the UCI indices which could mean that cooling effect is not solely dependent on wetland size, while moderate to very strong negative correlations were calculated between temperature difference and precipitation $(r=-0.48$ to -0.82$)$. Furthermore, rapid expansion of built-up areas at different sections along the river have resulted to reduced UCI scale $(\mathrm{r}=-0.37$ to -0.75$)$ and stronger cooling intensity $(\mathrm{r}=0.55$ to 0.84$)$.
\end{abstract}

\section{INTRODUCTION}

Rapidly increasing rate of urbanization, although considered as one of the indicators of economic growth in the Philippines, has led to detrimental effects on the urban thermal environment. The prevalence of impervious surfaces such as concrete and asphalt pavements, coupled with heightened anthropogenic heat emissions from vehicles and air-conditioning systems, has resulted to generally hotter temperatures in highly urbanized cities as compared to its surrounding rural areas. This substantial difference in temperature between urban and rural areas is one of the manifestations of the urban heat island (UHI) phenomenon (Tiangco et al., 2008). Intensified surface and air temperatures due to UHI could result to adverse direct and indirect impacts such as higher electricity and water consumption, worsening environmental quality, compromised thermal comfort, and sudden rise in heat-related morbidity and mortality cases (O’Malley et al., 2014).

In contrast to UHI, urban cooling islands (UCI) such as green and water spaces are areas within the urban regions with cooler surface temperatures compared with their neighboring landscapes (Ca et al., 1998). Many previous studies have already established that urban vegetation is capable of reducing its surrounding temperature through evapotranspiration and direct shading (Zoulia et al., 2009; Oliveira et al., 2011; Zhou et al., 2019) while limited researches focused on the cooling impact of water bodies since it is more common to manage green infrastructure within urban areas than to construct and maintain artificial water spaces. However, in terms of cooling efficiency, water bodies such as rivers, streams, reservoirs, and lakes are relatively more effective than green spaces due to its higher rate of evapotranspiration and thermal capacity (Sun et al., 2012).

Most of the available literature concentrated on assessing the UCI effect of urban water spaces using a single-date satellite image and only looked into its overall impact in relation to wetland structure and surrounding area characteristics (Lee et al., 2016; Zhang et al., 2017; Ekwe et al., 2019; Xue et al., 2019). These studies were not able to assess the differences in cooling effect over a long temporal data series and at distinct zones surrounding the water bodies. Moreover, meteorological conditions such as wind and precipitation were not considered by the previous studies as an important factor in UCI variation.

The main objective of the study is to investigate the spatiotemporal variation of the UCI effect of Iloilo River and adjacent wetlands on its surrounding landscape. Specifically, it aims to (1) analyze the differences in UCI effect of the water space at various image acquisition dates; (2) compare the cooling effect variation at different zones surrounding the river; and (3) evaluate the relationship of UCI indices with wetland geometry, meteorological factors, and land cover proportions. In doing so, the study will utilize satellite-derived land surface temperature (LST) layers since available historical air temperature data were obtained at a single weather station only and cannot be used in geospatial analysis. Studies show that air temperature is highly correlated with LST, hence, is often used to assess UHI effect at a given time over a broad area (Nichol and Wong, 2008; Weng, 2009). Through this study, the knowledge of urban planners on efficient management of urban water spaces for UHI mitigation shall be enhanced and the local government shall be guided on how to maximize the cooling effect of wetlands and other water bodies within Iloilo City. 


\section{DATA AND METHODS}

\subsection{Study Site}

Iloilo City $\left(10^{\circ} 45^{\prime} \mathrm{N}, 122^{\circ} 33^{\prime} \mathrm{E}\right)$ is a 78.34 -square kilometer, highly-urbanized city situated at the southwestern edge of the Province of Iloilo in Panay Island. It is considered as the center of the Metro Iloilo-Guimaras (MIG), the only officially recognized metropolitan area in the Western Visayas region. Based on the recent Comprehensive Land Use Plan of Iloilo City, majority of the city's land area is occupied by residential zones $(57.35 \%)$, followed by commercial zones $(8.21 \%)$, and park and open spaces $(5.50 \%)$. The city has a monsoonal climate consisting of dry and wet seasons with summer months from March to May. According to a 2010 climatological data from the Philippine Atmospheric, Geophysical and Astronomical Services Administration (PAG-ASA), the average temperature of the city throughout the year is $27.8^{\circ} \mathrm{C}$. Within the city lie three major water bodies namely: Jaro River, Batiano River, and Iloilo River.

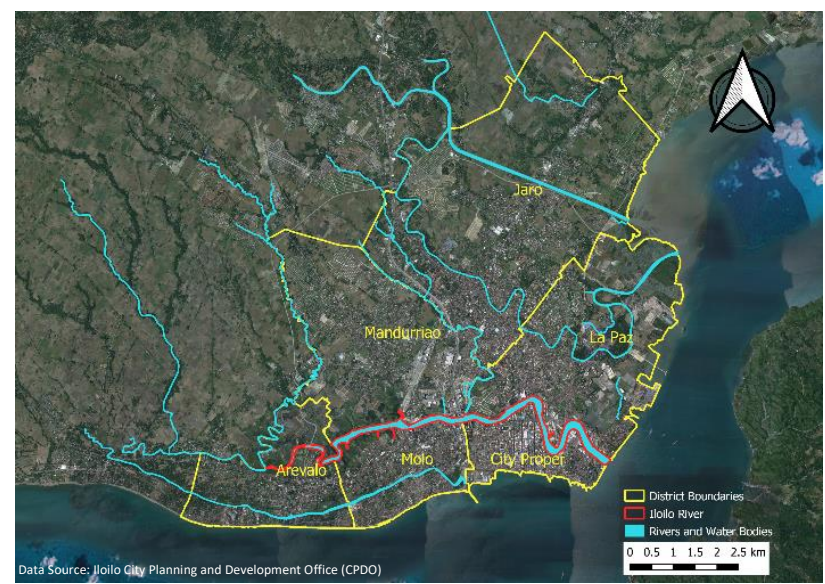

Figure 1. Map of the study site showing the administrative districts and the main water bodies in Iloilo City

\subsubsection{Iloilo River and Adjacent Wetlands}

Among the three major water bodies, the study will focus on Iloilo River and the wetlands adjacent to it since its unique physical characteristics makes it an ideal study site for UCI researches. It is a $15-\mathrm{km}$ estuary that navigates through five out of the six administrative districts of Iloilo City. It is surrounded by various land cover types such as vast agricultural lands in the Mandurriao district, nearby fishponds in the La Paz district, and built-up areas of varying density in the districts of Arevalo, Molo, and City Proper. Various mangrove species thrive within its riverbanks and it is surrounded by adjacent fishponds and salt beds. One of the on-going developments involving the estuary is the construction of the Iloilo River Esplanade, a riverside lateral park which aims to improve the walkability of the city. Adjacent wetlands were included in UCI analysis since the river and the surrounding fishponds were perceived to be continuous based on Landsat images.

\subsubsection{Subdivision of Surrounding Area into Zones}

As shown in Figure 2, the areas surrounding the Iloilo River and adjacent fishponds were divided into seven zones to determine its cooling effect to different areas with distinct composition of land cover classes. The zones were created so that the cooling effect to be observed will be coming mainly from the water bodies, and not the agricultural and vegetated areas. These green areas were separated so that an observation can be made whether water bodies have significant cooling effect not only on urban spaces, but on green spaces as well. Table 1 summarizes the visual characteristics of each surrounding zone.

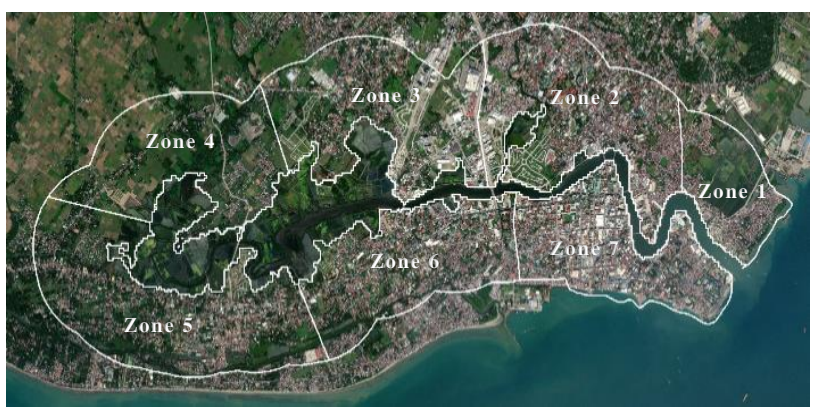

Figure 2. Delineated zones for the study

\begin{tabular}{|c|c|}
\hline Zone & Visual Characteristics \\
\hline 1 & $\begin{array}{l}\text { Relatively few built-up areas, moderate vegetation } \\
\text { areas, with nearby fishpond, near the coast }\end{array}$ \\
\hline 2 & $\begin{array}{l}\text { Dense built-up areas, moderate vegetation areas, } \\
\text { moderate water spaces }\end{array}$ \\
\hline 3 & $\begin{array}{l}\text { Moderate built-up areas, moderate vegetated areas, } \\
\text { recent development of business district }\end{array}$ \\
\hline 4 & $\begin{array}{c}\text { Relatively few built-up areas, large agricultural } \\
\text { areas }\end{array}$ \\
\hline 5 & $\begin{array}{c}\text { Moderate built-up areas, moderate vegetated areas } \\
\text { and water bodies, near the coast }\end{array}$ \\
\hline 6 & $\begin{array}{l}\text { Very dense built-up areas, few vegetation areas and } \\
\text { water spaces, near the coast }\end{array}$ \\
\hline 7 & $\begin{array}{l}\text { Very dense built-up areas, very few vegetation } \\
\text { areas, near the coast }\end{array}$ \\
\hline
\end{tabular}

\subsection{Data Used}

\subsubsection{Satellite Data}

To temporally assess the variation of UCI over a long period of time, the study utilized satellite images acquired using Landsat 5 TM, Landsat 7 ETM+, and Landsat 8 OLI/TIRS sensors with a spatial resolution of 30 meters and a temporal resolution of 16 days. Landsat satellite imageries were downloaded from the United States Geological Survey (USGS) Earth Explorer website (http://earthexplorer.usgs.gov). Seven cloud-free images acquired during the hot dry season (March to May) of Iloilo City were selected for processing.

\begin{tabular}{cc}
\hline Image & Landsat \\
Date & Sensor \\
\hline April 7, 1994 & Landsat 5 TM \\
May 4, 1998 & Landsat 5 TM \\
April 8, 2003 & Landsat 7 ETM+ \\
April 21, 2005 & Landsat 5 TM \\
April 1, 2013 & Landsat 8 OLI/TIRS \\
March 18, 2016 & Landsat 8 OLI/TIRS \\
May 14, 2019 & Landsat 8 OLI/TIRS \\
\hline
\end{tabular}

Table 2. Satellite images used

\subsubsection{Meteorological Data}

Wind speed and direction data for 1990-2009 were obtained from a PAG-ASA weather station in Iloilo City while the 20102019 data were acquired from Weather Underground (www.wunderground.com). Meanwhile, the Climate Hazards 
Group (CHG) InfraRed Precipitation with Station data (CHIRPS) - pentad dataset with a spatial resolution of 4.8 kilometers was obtained from Climate Engine (https://app.climateengine.org).

\begin{tabular}{cccc}
\hline $\begin{array}{c}\text { Image } \\
\text { Date }\end{array}$ & $\begin{array}{c}\text { Wind Speed } \\
(\mathrm{m} / \mathrm{s})\end{array}$ & $\begin{array}{c}\text { Wind } \\
\text { Direction }\end{array}$ & $\begin{array}{c}\text { Precipitation } \\
(\mathrm{mm} / \text { pentad })\end{array}$ \\
\hline $4 / 7 / 1994$ & 3 & $\mathrm{NE}$ & 43.85 \\
$5 / 4 / 1998$ & 3 & $\mathrm{SW}$ & 0.79 \\
$4 / 8 / 2003$ & 4 & $\mathrm{ENE}$ & 3.91 \\
$4 / 21 / 2005$ & 3 & $\mathrm{SSE}$ & 7.29 \\
$4 / 1 / 2013$ & 5 & $\mathrm{NE}$ & 15.11 \\
$3 / 18 / 2016$ & 5 & $\mathrm{NNE}$ & 2.40 \\
$5 / 14 / 2019$ & 5 & $\mathrm{NE}$ & 10.75 \\
\hline
\end{tabular}

Table 3. Meteorological data on the study site during each mage acquisition date

\subsection{Methodology}

The methodology of the study consists of three main steps: (1) image processing, (2) calculation of descriptors, and (3) Pearson correlation analysis.

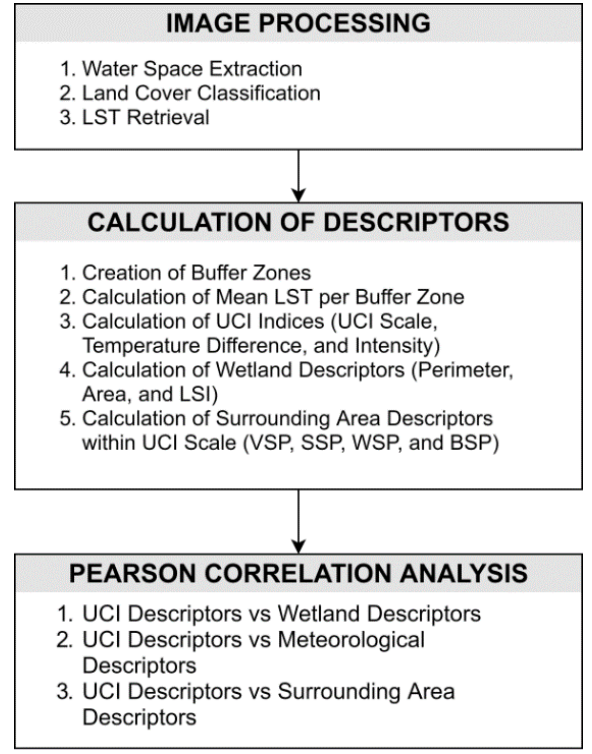

Figure 3. General workflow of the study

\subsubsection{Water Space Extraction}

To delineate the Iloilo River and adjacent wetlands for each image date, a simple thresholding process from the Short-Wave Infrared 1 (SWIR-1) band of Landsat scaled reflectance was used. Since the water absorbs light from the short-wave infrared region, the SWIR band can easily detect water bodies. By testing different threshold values, 1500 was identified as the optimal value for extracting the extent of water spaces. Fishponds that were still in preparation stage or did not have water during the date of image acquisition were not delineated
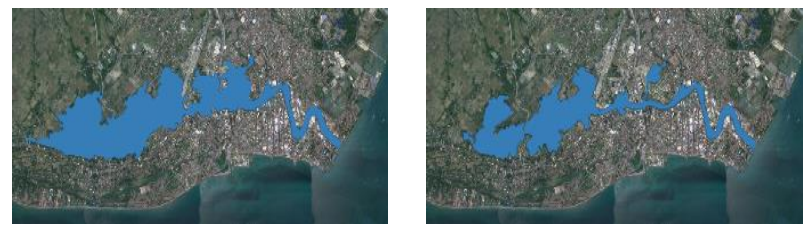

Figure 4. Delineated study area (blue polygon) from 1994 (left) and 2019 (right) satellite images since it could affect the average temperature of the wetlands.

\subsubsection{Calculation of Wetland Spatial Characteristics}

Using the extracted shapefiles of the water spaces, three spatial characteristics were calculated to describe the size (perimeter and area) and shape (landscape shape index) of the wetlands. Landscape shape index (LSI) was calculated using the formula:

$$
L S I=\frac{P}{2 \sqrt{A \times \pi}}
$$

where $L S I$ is the landscape shape index, $P$ is the wetland perimeter $(\mathrm{m})$, and $A$ is the wetland area $\left(\mathrm{m}^{2}\right)$. A higher LSI value indicates a more complex wetland shape.

\subsubsection{Land Cover Classification}

Downloaded satellite images were classified into six classes (vegetation, bare soil, water, built-up, clouds, and cloud shadows). Prior to classification, the images were radiometrically calibrated and atmospherically corrected using Fast Line-of-sight Atmospheric Analysis of Hypercubes (FLAASH) in ENVI 5.1. To improve the separability of each land cover class, three spectral indices were derived from each image: Normalized Difference Vegetation Index (NDVI), Normalized Difference Water Index (NDWI), and Normalized Difference Built-up Index (NDBI). Support vector machine (SVM) algorithm was performed and the resulting classified images were validated using samples that were created based on visual interpretation.

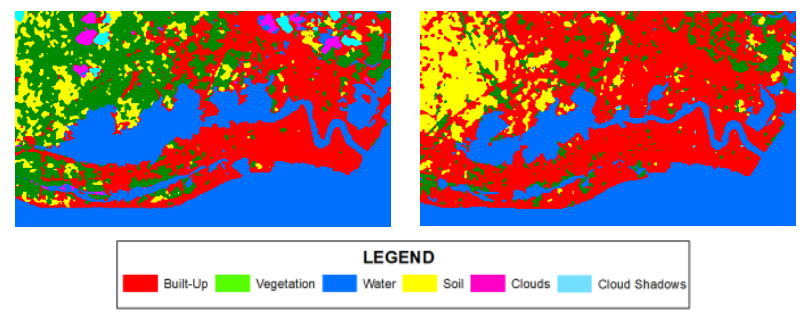

Figure 5. Land cover classification of Iloilo City in 1994 (left) and 2019 (right)

\subsubsection{Calculation of Surrounding Area Characteristics}

Four land cover proportions were computed to define the surrounding area characteristics in each zone per satellite image date: Vegetation Surface Proportion (VSP), Soil Surface Proportion (SSP), Water Surface Proportion (WSP), and Builtup Surface Proportion (BSP). These values were calculated by dividing the area of each land cover by the total area within the UCI scale.

\subsubsection{Land Surface Temperature (LST) Retrieval}

Land surface temperature (LST) layers were derived from the downloaded Landsat images to show the skin temperature on the surface of a large area instead of obtaining in-situ temperature measurements. Google Earth Engine (GEE), a cloud-computing platform for remote sensing applications and geospatial analysis, was used in processing the images. The study adopted the method developed by Jeevalakshmi et al. (2017) which utilized brightness temperature (BT) and land surface emissivity (LSE) to calculate LST using the formula: 


$$
T_{S}=\frac{B T}{\left\{1+\left[\left(\frac{\lambda B T}{\rho}\right) \ln \varepsilon_{\lambda}\right]\right\}}
$$

where $T_{s}$ is the land surface temperature $\left({ }^{\circ} \mathrm{C}\right), B T$ is the atsensor brightness temperature $\left({ }^{\circ} \mathrm{C}\right), \lambda$ is the average wavelength of thermal band, $\varepsilon_{\lambda}$ is the land surface emissivity and $\rho=1.438$ x $\left.10^{-2} \mathrm{mK}\right)$.

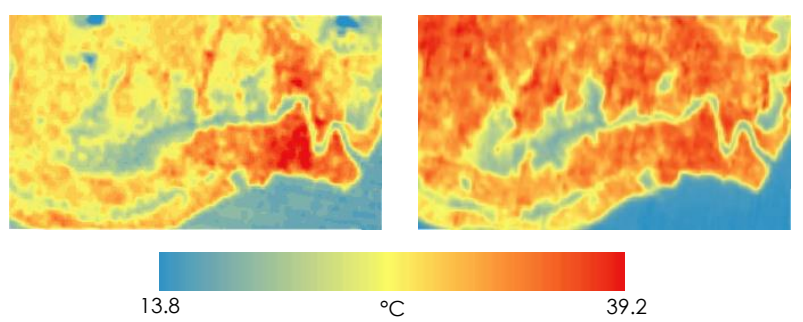

Figure 6. Landsat-derived LST layers from 1994 (left) and 2019 (right) satellite images

\subsubsection{Calculation of LST per Buffer Zone}

Twenty buffer zones with a distance of $50 \mathrm{~m}$ from the edge of the previous buffer zone up to a maximum distance of $1000 \mathrm{~m}$ were generated. The buffers were used primarily as a way to determine how much the cooling effect of the river is as the distance from the boundary of the water space increases. The average LST values were computed for each buffer zone within each of the seven delineated zones for each image acquisition date.

\subsubsection{Calculation of Urban Cooling Island (UCI) Indices}

To quantify the cooling effect of water spaces, three UCI indices proposed by Sun et al. (2012) were calculated for each zone and image acquisition date: scale, temperature difference, and intensity. UCI scale is the maximum distance from the edge of the water body that is influenced by its cooling effect. It is determined by plotting LST against the distance from water body and selecting the first inflection point of the curve. The first turning point was selected since the fluctuations in the curve at farther distances could be due to other cooling factors other than the river (i.e. coastal waters). Temperature difference refers to the difference between the average temperature of the water body and the mean temperature of the buffer zone of the identified UCI scale. UCI intensity is temperature gradient within the influence scale and is calculated by dividing the temperature difference by the UCI scale.

\section{RESULTS AND DISCUSSION}

\subsection{Wetland Spatial Characteristics}

The average temperatures of the water spaces during the selected satellite image dates illustrate the increasing trend of LST in Iloilo City during the hot dry season. An overall increase of $4.39{ }^{\circ} \mathrm{C}$ in water surface temperature (WST) was observed from April 7, 1994 to May 14, 2019. On the other hand, there is a significant decline in the area covered by Iloilo River and surrounding wetlands as shown in Figure 4. The total area decreased from 725.40 ha in 1994 to 481.15 ha in 2019 , having a difference of 244.25 ha. Similarly, its perimeter was reduced by $2.97 \mathrm{~km}$ in a span of 25 years. Meanwhile, its landscape shape index increased from 4.99 to 5.75 which indicate that the overall shape of the water space became more complex.
Extensive changes in the geometry of the water space could be mainly attributed to the rapid urban development in Iloilo City. From the satellite images, it can be observed that some fishponds near the river were already converted to built-up areas. Portions of the river were also reclaimed for the construction of the Iloilo River Esplanade which began on 2011. In addition to land cover-land use conversion, variations in the size of the wetlands may also be because dry fishponds during the satellite image acquisition were not included in the feature extraction.

\begin{tabular}{ccccc}
\hline $\begin{array}{c}\text { Image } \\
\text { Date }\end{array}$ & $\begin{array}{c}\text { LST } \\
\left({ }^{\circ} \mathrm{C}\right)\end{array}$ & $\begin{array}{c}\text { Perimeter } \\
(\mathrm{km})\end{array}$ & $\begin{array}{c}\text { Area } \\
(\mathrm{ha})\end{array}$ & LSI \\
\hline $4 / 7 / 1994$ & 24.76 & 47.66 & 725.40 & 4.99 \\
$5 / 4 / 1998$ & 26.11 & 47.46 & 623.87 & 5.36 \\
$4 / 8 / 2003$ & 27.81 & 47.69 & 556.56 & 5.70 \\
$4 / 21 / 2005$ & 27.31 & 47.48 & 553.98 & 5.69 \\
$4 / 1 / 2013$ & 25.66 & 49.85 & 561.72 & 5.93 \\
$3 / 18 / 2016$ & 29.27 & 43.27 & 456.73 & 5.71 \\
$5 / 14 / 2019$ & 29.15 & 44.69 & 481.15 & 5.75 \\
\hline
\end{tabular}

Table 4. Spatial characteristics of Iloilo River and adjacent wetlands during each image acquisition date

\subsection{Urban Cooling Island (UCI) Indices}

From Figure 7, the graph shows that the land surface temperature at each zone gradually increases until it reaches its turning distance wherein the direction of the curve changes or becomes relatively flat. This proves that the Iloilo River provides cooling effect to its surrounding areas and it weakens with increasing buffer distance until it reaches the UCI scale. Beyond its cooling extent, uniform LST values signify that the river contributes insignificant effect in lowering the temperature within the area while the reduction in surface temperature in the succeeding buffer zones could be influenced by another water space or green space. In Zone 1 for example, the drop in mean LST values from $150 \mathrm{~m}$ to $400 \mathrm{~m}$ is due to a nearby fishpond within the area. Similarly, the sudden decline in LST from 600 $\mathrm{m}$ to $850 \mathrm{~m}$ in Zone 5 is due to the presence of another water body. It is worth noting that Zone 7 shows a similar trend even if very high built-up density exists within the buffer zone nearest to the river edge. This verifies that the UCI effect not only manifests in air temperature, but also in the surface temperature of different land cover types.

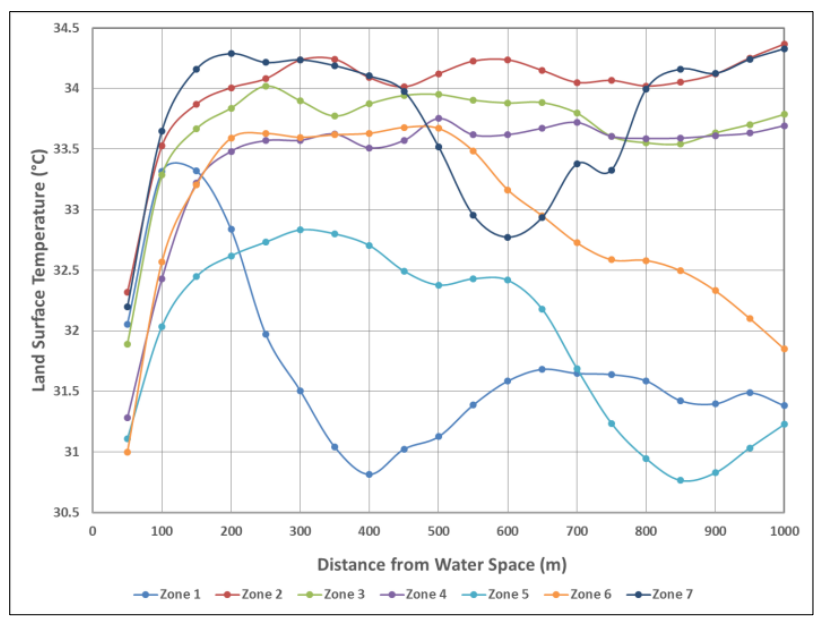

Figure 7. Plot of land surface temperature vs distance from water space obtained from the May 14, 2019 LST layer 


\subsubsection{Spatial Variation}

Evidently, different areas near the river with distinct surface characteristics experience varying UCI effect. Among the seven zones, the highest average cooling scale was experienced in Zone $5(321.43 \mathrm{~m})$, which is located southeast of Iloilo River and is characterized by slightly heavy built-up area coverage and moderate vegetation. Zone 1 obtained the least UCI scale $(121.43 \mathrm{~m})$ and highest cooling intensity $\left(0.03{ }^{\circ} \mathrm{C} / \mathrm{m}\right)$. The reduction of its scale may be due to the presence of a neighboring fishpond which has its individual cooling effect on its surrounding areas. Expectedly, the highest deviation from the average temperature of the water space was calculated in Zone 7 $\left(4.82^{\circ} \mathrm{C}\right)$, which houses extensive built-up areas within the City Proper. Meanwhile, the lowest mean temperature difference and UCI intensity was in Zone $4\left(3.34{ }^{\circ} \mathrm{C}\right.$ and $0.01{ }^{\circ} \mathrm{C} / \mathrm{m}$, respectively), which is mostly made up of vegetated lands and bare soil.

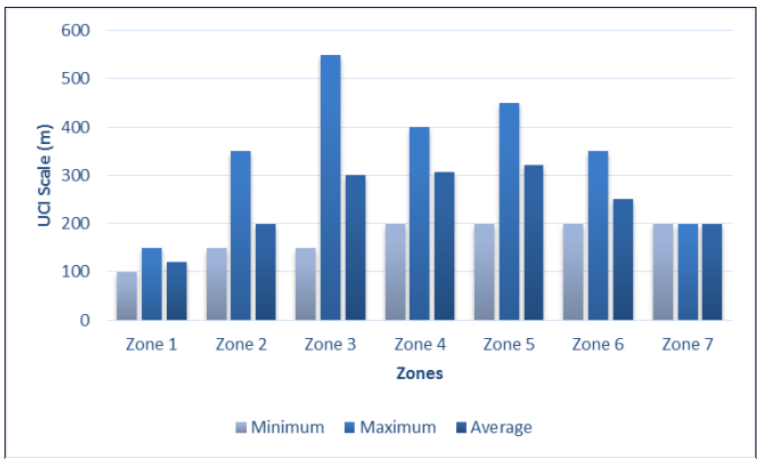

(a)

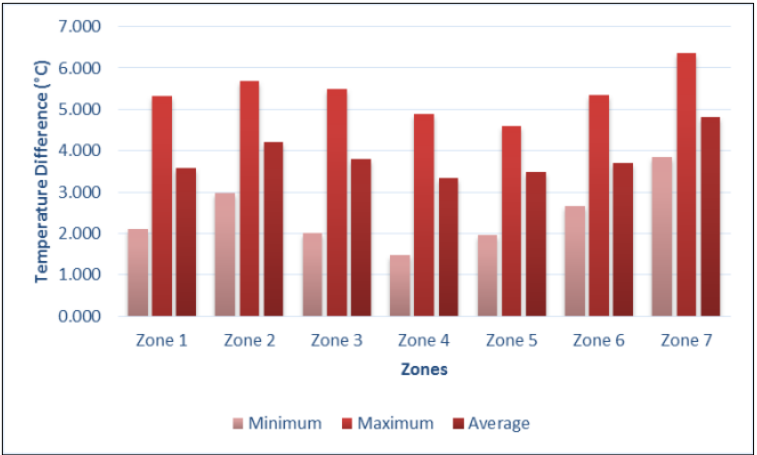

(b)

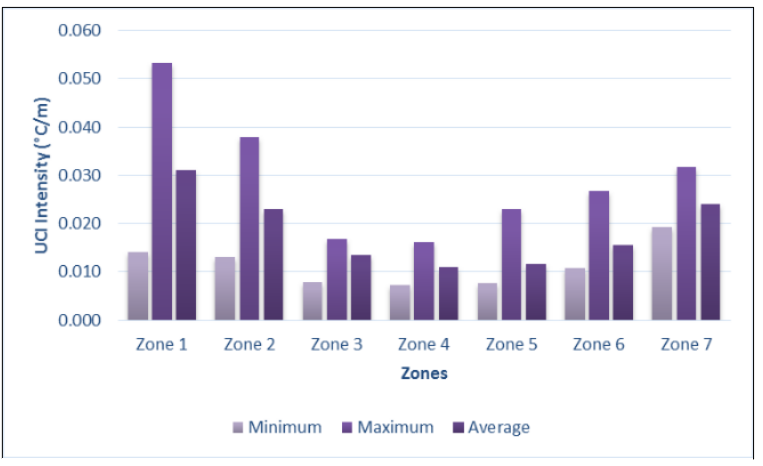

(c)

Figure 8. Minimum, maximum, and average (a) scale, (b) temperature difference, and (c) intensity per zone

\subsubsection{Temporal Variation}

Results show that the cooling effect of water spaces also vary at different image dates during the hot dry season of Iloilo City. The lowest average UCI scale $(185.71 \mathrm{~m})$, temperature difference $\left(2.48{ }^{\circ} \mathrm{C}\right)$, and intensity $\left(0.01{ }^{\circ} \mathrm{C} / \mathrm{m}\right)$ were calculated on the satellite image taken on April 7, 1994. Based on the CHIRPS dataset, a total of $43.85 \mathrm{~mm}$ of precipitation was recorded within the pentad, which could have lowered the temperature of the surrounding areas, thus resulting to weaker cooling effect on that day. On the contrary, the highest average UCI scale was obtained during May 14, 2019 (264.29 m) while the highest temperature difference $\left(5.39^{\circ} \mathrm{C}\right)$ and intensity $(0.03$ ${ }^{\circ} \mathrm{C} / \mathrm{m}$ ) were experienced on April 8, 2003. Temporal variation in the cooling effect of the river could possibly be due to various climatological factors such as wind speed, wind direction, and amount of rainfall.

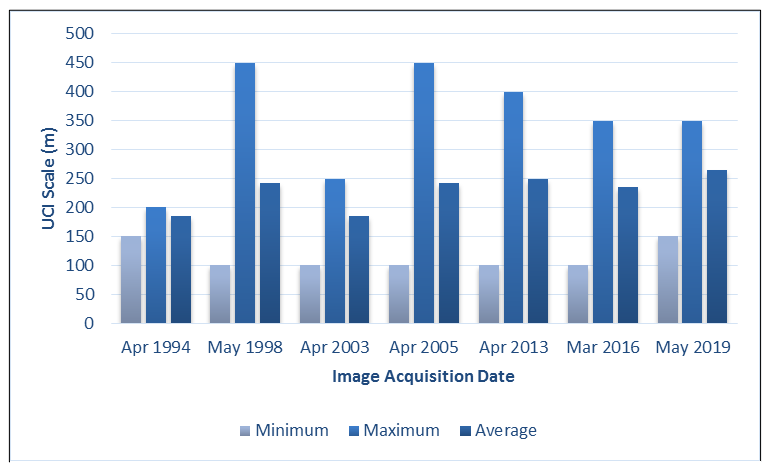

(a)

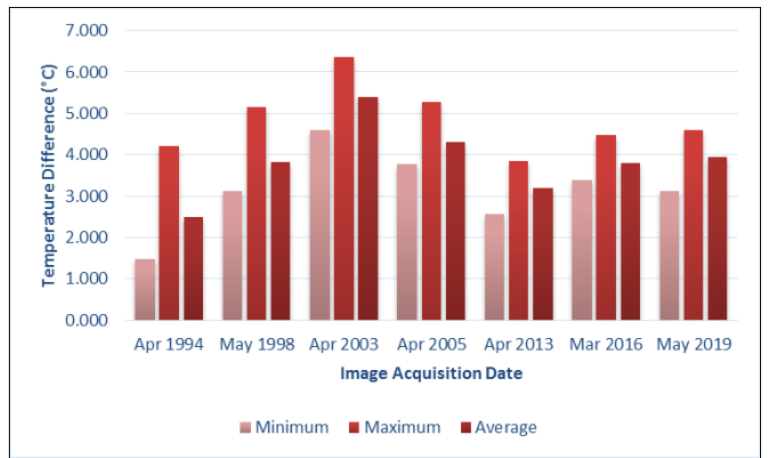

(b)

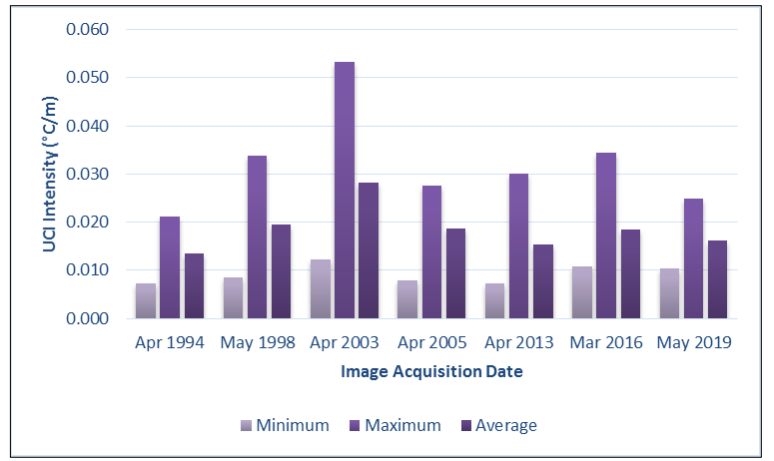

(c)

Figure 9. Minimum, maximum, and average (a) scale, (b) temperature difference, and (c) intensity per image date 


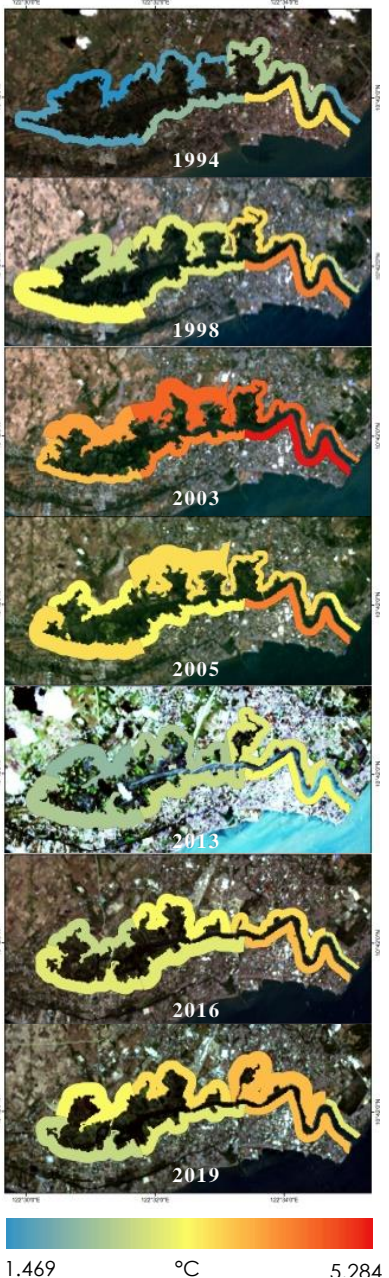

(a)

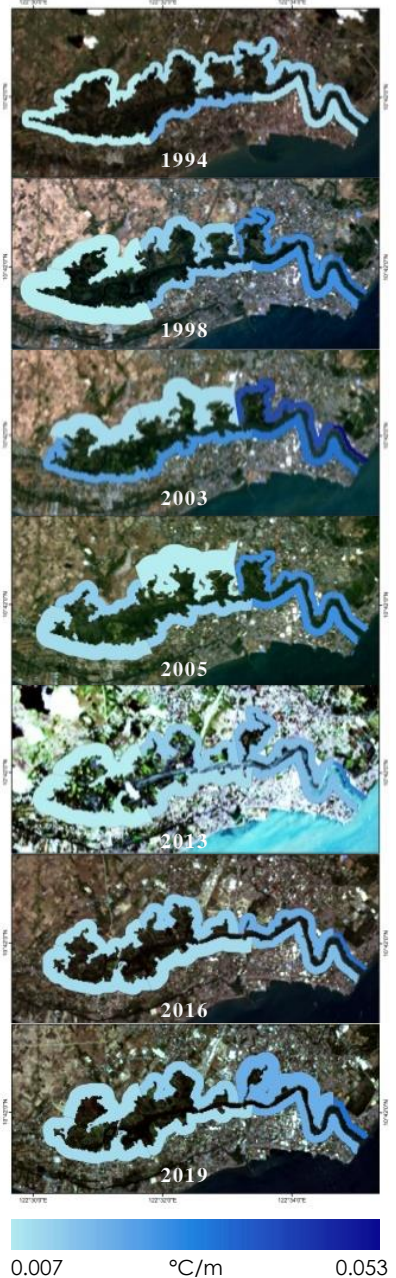

(b)
Figure 10. UCI scale and (a) temperature difference and (b) UCI intensity of each zone for each satellite image date

\subsection{Relationship between UCI Indices and Wetland Spatial Characteristics}

Sun et al. (2012) revealed that wetland size and shape influence its cooling effect to the surrounding areas. However, Table 5 shows that very weak to moderate correlation values were calculated between UCI indices and wetland spatial characteristics for each zone. Also, only the relationship between the temporal influence scale and wetland area in Zone 6 was determined to be statistically significant at a $5 \%$ level of significance. The difference in results could be because the current study analyzed the spatial characteristics of a single wetland at different years while the study by Sun et al. (2012) compared various water spaces such as rivers, reservoirs, and lakes with areas ranging from 46 ha to 9868 ha at a single satellite image date.

Interestingly, an overall negative relationship can be observed between the area of the wetland and the cooling indices, which is consistent with previous findings. This could indicate that a larger water space does not necessarily result to stronger cooling effect. Also, this could mean that the decrease in area of Iloilo River and adjacent wetlands has a minor impact on its performance as an urban cooling island.

\begin{tabular}{ccccc}
\hline \multirow{2}{*}{$\begin{array}{c}\text { Dependent } \\
\text { Variable }\end{array}$} & Zone & \multicolumn{3}{c}{ Independent Variable } \\
& Zerimeter & Area & LSI \\
\hline \multirow{5}{*}{ Scale } & -0.11 & 0.22 & -0.34 \\
& Zone 2 & -0.46 & -0.38 & 0.18 \\
& Zone 3 & 0.06 & -0.27 & 0.35 \\
& Zone 4 & 0.23 & -0.31 & 0.53 \\
& Zone 5 & 0.22 & -0.15 & 0.31 \\
& Zone 6 & -0.42 & $-\mathbf{0 . 6 9}$ & 0.60 \\
& Zone 7 & -- & -- & -- \\
\hline \multirow{5}{*}{ Temperature } & Zone 1 & -0.09 & -0.50 & 0.53 \\
Difference & Zone 2 & -0.17 & -0.51 & 0.48 \\
& Zone 3 & -0.28 & -0.62 & 0.55 \\
& Zone 4 & -0.24 & -0.64 & 0.60 \\
& Zone 5 & 0.01 & -0.43 & 0.50 \\
& Zone 6 & -0.01 & -0.43 & 0.44 \\
& Zone 7 & 0.05 & -0.04 & 0.04 \\
\hline \multirow{5}{*}{ Intensity } & Zone 1 & 0.01 & -0.40 & 0.48 \\
& Zone 2 & 0.25 & -0.01 & 0.14 \\
& Zone 3 & -0.44 & -0.28 & 0.07 \\
& Zone 4 & -0.46 & -0.58 & 0.38 \\
& Zone 5 & -0.08 & -0.16 & 0.15 \\
& Zone 6 & 0.19 & 0.01 & -0.03 \\
& Zone 7 & 0.05 & -0.04 & 0.04 \\
\hline
\end{tabular}

Table 5. Summary of Pearson correlation analysis between

$\mathrm{UCI}$ indices and wetland spatial characteristics ( $\mathrm{r}$ values in bold text are statistically significant with $\mathrm{p}<0.05$ )

\subsection{Relationship between UCI Indices and Meteorological Conditions}

As expected, the amount of precipitation significantly reduced the temperature of the areas within the influence scale of the river. Moderate to very strong negative correlations $(r=-0.48$ to $r=-0.82$ ) between temperature difference and precipitation for each zone were observed. Only zones 1-5 obtained statistically significant correlation values at $5 \%$ level of significance. This could be because zones 6 and 7 consists of very dense residential and commercial areas made up of impervious building materials, thus, the amount of precipitation

\begin{tabular}{cccc}
\hline $\begin{array}{c}\text { Dependent } \\
\text { Variable }\end{array}$ & Zone & \multicolumn{2}{c}{ Independent Variable } \\
& Zone 1 & -0.08 & 0.54 \\
& Zone 2 & 0.40 & 0.16 \\
Scale & Zone 3 & -0.16 & -0.49 \\
& Zone 4 & 0.03 & -0.57 \\
& Zone 5 & $\mathbf{- 0 . 7 1}$ & -0.48 \\
Zone 6 & $\mathbf{- 0 . 7 1}$ & -0.28 \\
Temperature & Zone 7 & -- & -- \\
Difference & Zone 1 & -0.19 & $\mathbf{- 0 . 7 0}$ \\
& Zone 2 & -0.18 & $\mathbf{- 0 . 7 0}$ \\
& Zone 3 & -0.06 & $\mathbf{- 0 . 7 7}$ \\
& Zone 4 & 0.00 & $\mathbf{- 0 . 7 7}$ \\
& Zone 5 & 0.02 & $\mathbf{- 0 . 8 2}$ \\
& Zone 6 & 0.32 & -0.64 \\
& Zone 7 & 0.54 & -0.48 \\
\hline \multirow{5}{*}{ Intensity } & Zone 1 & -0.22 & $\mathbf{- 0 . 7 1}$ \\
& Zone 2 & -0.44 & -0.55 \\
& Zone 3 & 0.36 & -0.01 \\
& Zone 4 & 0.14 & -0.55 \\
& Zone 5 & 0.66 & -0.26 \\
& Zone 6 & $\mathbf{0 . 6 7}$ & -0.31 \\
& Zone 7 & 0.54 & -0.48 \\
\hline
\end{tabular}

Table 6. Summary of Pearson correlation analysis between UCI indices and meteorological conditions ( $\mathrm{r}$ values in bold text are statistically significant with $p<0.05)$ 
in these zones is not a major factor in lowering the temperature difference. Similarly, the result of the Pearson correlation analysis shows that the cooling intensity of the water space was also weaker during days with greater amount of rainfall.

On the other hand, the correlation values between UCI indices and wind vector data were inconsistent for each zone. Among the seven zones, only Zones 5 and 6 obtained statistically significant correlation values at $5 \%$ significance level $(-0.71$ and -0.71 , respectively). This could be because the effect of wind speed and direction is more evident in air temperature data, whereas the study used LST values in analysing UCI. Moreover, the wind data used were obtained from two different sources: PAG-ASA weather station near the now-defunct Mandurriao Airport (1990-2009) and Weather Underground weather station in Iloilo International Airport (2010-2019). Since the stations are quite far from the study site, the acquired data did not accurately represent the actual wind velocity at the time of image acquisition.

\subsection{Relationship between UCI Indices and Surrounding Area Characteristics}

The amount of pervious and impervious areas within the cooling extent of the Iloilo River significantly impact its cooling efficiency as confirmed by the result of the correlation analysis between UCI indices and land cover proportion as shown in Table 7. Strong to very strong positive correlations were observed between UCI scale and vegetation surface proportion except for $1994(r=0.65-0.90)$ which means that an increase in green spaces could extend the influence scale of the river up to a certain distance. Meanwhile, a negative relationship can be perceived between VSP and temperature difference $(r=-0.30$ -

\begin{tabular}{|c|c|c|c|c|c|}
\hline \multirow{2}{*}{$\begin{array}{l}\text { Dependent } \\
\text { Variable }\end{array}$} & \multirow{2}{*}{ Year } & \multicolumn{4}{|c|}{ Independent Variable } \\
\hline & & VSP & SSP & WSP & BSP \\
\hline \multirow{7}{*}{ Scale } & 1994 & 0.07 & 0.19 & -0.45 & -0.08 \\
\hline & 1998 & 0.90 & 0.58 & -0.84 & -0.73 \\
\hline & 2003 & 0.67 & 0.77 & -0.61 & -0.75 \\
\hline & 2005 & 0.65 & 0.41 & -0.62 & -0.50 \\
\hline & 2013 & 0.79 & 0.50 & -0.70 & -0.65 \\
\hline & 2016 & 0.66 & 0.20 & -0.50 & -0.37 \\
\hline & 2019 & 0.66 & 0.56 & -0.79 & -0.57 \\
\hline \multirow{7}{*}{$\begin{array}{l}\text { Temperature } \\
\text { Difference }\end{array}$} & 1994 & -0.72 & -0.65 & -0.09 & 0.76 \\
\hline & 1998 & -0.34 & -0.61 & -0.02 & 0.62 \\
\hline & 2003 & -0.78 & -0.52 & 0.23 & 0.60 \\
\hline & 2005 & -0.30 & -0.18 & -0.07 & 0.26 \\
\hline & 2013 & -0.66 & -0.73 & 0.01 & 0.75 \\
\hline & 2016 & -0.50 & -0.46 & -0.10 & 0.55 \\
\hline & 2019 & -0.48 & -0.05 & -0.46 & 0.26 \\
\hline \multirow{7}{*}{ Intensity } & 1994 & -0.80 & -0.77 & 0.09 & 0.84 \\
\hline & 1998 & -0.91 & -0.71 & 0.78 & 0.84 \\
\hline & 2003 & -0.80 & -0.73 & 0.80 & 0.73 \\
\hline & 2005 & -0.83 & -0.53 & 0.67 & 0.65 \\
\hline & 2013 & -0.84 & -0.58 & 0.82 & 0.72 \\
\hline & 2016 & -0.80 & -0.41 & 0.71 & 0.55 \\
\hline & 2019 & -0.85 & -0.50 & 0.59 & 0.61 \\
\hline
\end{tabular}

Table 7. Summary of Pearson correlation analysis between UCI indices and Land cover proportions - vegetation surface proportion (VSP), soil surface proportion (SSP), water surface proportion (WSP), and built-up surface proportion (BSP) ( $\mathrm{r}$ values in bold text are statistically significant with $\mathrm{p}<0.05$ )
$-0.78)$ and intensity $(r=-0.80--0.91)$, indicating that the amount of vegetation within the scale significantly lowers the temperature of these areas, and as a result, reduces the temperature gradient. A similar but generally weaker relationship can be observed between the indices and bare soil proportion. Conversely, the fraction of built-up areas reduces the influence scale of the urban cooling island as supported by the negative correlations between scale and built-up surface proportion. Meanwhile, as expected, a positive relationship exists between temperature difference and intensity and BSP, which means that areas with more extensive built-up cover will result to higher surface temperature compared to the water body, and stronger cooling intensity.

Another remarkable finding of the study is the relationship that occurs between the proportion of water within the cooling extent of the river and the UCI indices. Results show that the higher the water surface proportion is, the shorter will be the UCI scale and the higher will be its corresponding cooling intensity. This could be because the method developed by Sun et al. (2012) selects the first inflection point of the LST-distance curve and does not consider the distances wherein a different water space jointly contributes its own cooling effect with Iloilo River.

\subsection{Implications for Urban Planning}

The results of the study provide significant implications for urban planning and water space management in Iloilo City. The study has demonstrated that water bodies, particularly, the Iloilo River and the wetlands adjacent to it, are capable of mitigating the effects of UHI by cooling its surrounding regions. In relation to this, the study also found out that wetland area is not significantly correlated with its UCI effect. This implies that increasing the size of the wetland could not improve its cooling effect. Hence, urban planners should consider building small but numerous artificial water spaces that are evenly distributed and strategically placed within the city instead of creating large but few water bodies which is also more difficult to accomplish considering the rapid conversion of open spaces to residential and commercial infrastructures. Man-made water spaces should be constructed within zones with dense built-up density that are far from inland and coastal waters since these regions are severely affected by UHI. In addition, existing lakes, rivers, streams, and other wetlands within the city should be maintained and upgraded by adding green spaces on its surroundings to improve its cooling efficiency. Lastly, the local government should also regulate the conversion of agricultural lands and open spaces to residential and commercial zones since the study has shown that impervious surfaces such as buildings and roads substantially increase the temperature in urban areas. The optimal spatial arrangement of water spaces and green spaces within urban areas should be prioritized by planners and developers in their landscape design to maximize its cooling effect to the urban environment.

\section{CONCLUSION AND RECOMMENDATIONS}

The study has confirmed that Iloilo River and the adjacent fishponds aids in UHI mitigation. Its cooling effect reduces as the distance from the water extent increases until it reaches the edge of its influence scale. Results of the study also show that the UCI effect varies both spatially and temporally, as evidenced by the differences in UCI indices calculated at various image dates and delineated regions. The scale of the UCI effect covers longer distances in agricultural areas while higher temperature differences and UCI intensity can be experi- 
enced in zones with high built-up density. Different factors such as wetland spatial characteristics, meteorological conditions, and surrounding area characteristics can affect the performance of water spaces as a UCI. Increasing the area of water spaces may not bring significant improvement in cooling effect. It is more efficient to have smaller water spaces distributed across the urban area instead of a one large water space. A good comparable example to this is the seas, where even if it is very big water space, only the areas near the shore can feel its breeze. Both precipitation and pervious surfaces (vegetation, bare soil, and water) significantly reduces the temperature of the surrounding areas, which in turn, lowers the temperature gradient in these zones. These findings are critical in the design and management of natural and artificial water spaces in Iloilo City for UHI mitigation.

It is recommended to utilize additional satellite images and subdivide the surrounding areas into smaller zones for the spatiotemporal analysis to increase the sample size and strengthen the established relationships between UCI indices and different independent variables. For future work, the study requires further exploration, especially on the relation of air temperature with LST. Due to the lack of adequate number of meteorological stations in the area, a model converting LST to air temperature was not derived. In addition, a wind model can be developed to more accurately determine its impact on the UCI effect of water spaces. Acquisition of ground measurements of air temperature and other meteorological data is recommended to further expand the research on UCI.

\section{ACKNOWLEDGEMENTS}

This research is part of the Geospatial Assessment and Modelling of Urban Heat Islands in Philippine Cities (Project GUHeat) with Project No. 4028, 2019, funded by the Philippine Council for Industry, Energy and Emerging Technology Research and Development - Department of Science and Technology (PCIEERD - DOST). Utmost acknowledgement is given to the City Planning and Development Office (CPDO) of Iloilo City for giving relevant documents and insights for the improvement of the study, and to Philippine Atmospheric, Geophysical and Astronomical Services Administration (PAGASA) for providing meteorological data.

\section{REFERENCES}

Ca, V. T., Asaeda, T., Abu, E. M., 1998. Reductions in air conditioning energy caused by a nearby park. Energy and Buildings, 29(1), 83-92.

Ekwe, M.C., Ibrahim, A.T., Balogun, I.A., Adedeji, O.I., Ekwe, D.O., Nom, J., 2019. Assessment of Urban Cooling Island Effects of Jabi Lake Reservoir, Abuja on its Surrounding Microclimate using Geospatial Techniques. Global Journal of Science Frontier Research: A Physics and Space Science, 19(2) Version 1.0, 36-48.

Jeevalakshmi, D., Narayana Reddy, S., Manikiam, B., 2017. Land Surface Temperature Retrieval from LANDSAT data using Emissivity Estimation. International Journal of Applied Engineering Research, Volume 12, Number 20, 9679-9687. http://www.ripublication.com/ijaer17/ijaerv12n20_57.pdf

Iloilo City Planning and Development Office, 2011. 2011-2020 Iloilo City Comprehensive Land Use Plan (CLUP).
Lee, D., Oh, K., Seo, J., 2016. An Analysis of Urban Cooling Island (UCI) Effects by Water Spaces Applying UCI Indices. International Journal of Environmental Science and Development, Vol. 7, No. 11, 810-815. doi: 10.18178/ijesd.2016. 7.11.886.

Manteghi, G., Limit, H., Remaz, D., 2015. Water Bodies an Urban Microclimate: A Review. Modern Applied Science, 9(6), 1-12. doi.org/10.5539/mas.v9n6p1.

Nichol, J.E., Wong, M.S., 2008. Spatial variability of air temperature and appropriate resolution for satellite-derived air temperature estimation. International Journal of Remote Sensing, 29, 7213-7223.

O’Malley, C., Piroozfarb, P. A. E., Farr, E. R. P., Gates, J., 2014. An investigation into Minimizing Urban Heat Island (UHI) effects: A UK perspective. Energy Procedia, 62(1), 7280. doi.org/10.1016/j.egypro.2014.12.368.

Oliveira, S., Andrade, H., Vaz, T., 2011. The cooling effect of green spaces as a contribution to the mitigation of urban heat: A case study in Lisbon. Building and Environment, 46, 21862194. doi.org/10.1016/j.buildenv.2011.04.034.

Sun, R., Chen, A., Chen, L., Lü, Y., 2012. Cooling effects of wetlands in an urban region: The case of Beijing. Ecological Indicators: Integrating Sciences for Monitoring, Assessment and Management, 20, 57-64. doi:10.1016/j.ecolind.2012.02. 006.

Sun, R., Chen, L., 2012. How can urban water bodies be designed for climate adaptation? Landscape and Urban Planning, 105, 27-33.

Tiangco, M., Lagmay, A.M., Argete, J. 2008. ASTER-based study of the night-time urban heat island effect in Metro Manila. International Journal of Remote Sensing, 29(10), 2799-2818. doi.org/10.1080/01431160701408360.

Weng, Q., 2009. Thermal infrared remote sensing for urban climate and environmental studies, methods, applications, and trends. ISPRS J. Photogramm. 64, 335-344.

Xue, Z., Hou, G., Zhang, Z., Lyu, X., Jiang, M., Zou, Y., Shen, X., Wang, J., Liu, X., 2019. Quantifying the cooling-effects of urban and peri-urban wetlands using remote sensing data: Case study of cities of Northeast China. Landscape and Urban Planning: An International Journal of Landscape Science, $\begin{array}{lll}\text { Planning and Design, 182, 92-100. } & \end{array}$ doi.org/10.1016/j.landurbplan.2018.10.015.

Zhang, Q., Wu, Z., Guo, G., 2017. The Cooling Effect of Water Landscape in High-density Urban Built-up Area: A Case Study of the Center Urban District of Guangzhou. 2017 2nd International Conference on Frontiers of Sensors Technologies (ICFST), 394-400. doi.org/10.1109/icfst.2017.8210543.

Zhou, W., Cao, F., Wang, G., 2019. Effects of Spatial Pattern of Forest Vegetation on Urban Cooling in a Compact Megacity. Forests, 10(3), 282. doi.org/10.3390/f10030282

Zoulia, I., Santamouris, M., Dimoudi, A., 2009. Monitoring the effect of urban green areas on the heat island in Athens. Environmental Monitoring and Assessment, 156(1-4), 275-292. 